\title{
LAS COOPERATIVAS DE CRÉDITO Y SU POSICIÓN DENTRO \\ DEL MODELO COOPERATIVO. INTEGRACIÓN FRENTE A \\ DIFERENCIACIÓN EN EL MARCO DE LA REFORMA DEL SISTEMA FINANCIERO ${ }^{1}$
}

\author{
POR \\ Carlos VARGAS VASSEROT ${ }^{2}$
}

\section{RESUMEN}

En el presente trabajo se van a exponer algunos aspectos del marco legal de las cooperativas de crédito, exponiendo su origen a mitad del siglo XIX en lo que hoy es Alemania y la recepción y evolución de la institución en España hasta llegar a la convulsa situación actual, en la que, tras la crisis financiera vivida en los últimos años, se debate de manera intensa cuál debe ser el futuro del sector con una anunciada reforma de su régimen legal.

Palabras clave: cooperativas de crédito, cajas rurales, Raifeissen, reforma del sistema financiero, integración, crédito cooperativo, crisis financiera

Claves Econlit: P 130, G300, G380

\footnotetext{
1 Trabajo realizado en el marco del Proyecto de I+D del MINECO sobre "Integración cooperativa y reestructuraciones socialmente responsables" (DER2013-48864-C2-1-P) y del Grupo de Investigación SEJ-200 de la Junta de Andalucía, "Derecho Público y Privado de la Agroalimentación y de la Innovación" adscrito al Campus Internacional ceiA3 de Agroalimentación.

${ }^{2}$ Catedrático Acr. Derecho Mercantil Universidad de Almería. Dirección de correo electrónico: cvargas@ual.es. REVESCO $\mathrm{N}^{\mathrm{o}} 117$ - MONOGRÁFICO: Las sociedades cooperativas construyen un mundo mejor - ISSN: 1885-8031 - www.ucm.es/info/revesco
}

http://dx.doi.org/10.5209/rev_REVE.2015.v117.48145

Fecha de recepción: 17/12/2014

Fecha de aceptación: 23/12/2014 


\title{
CREDIT UNIONS AND ITS POSITION WITHIN THE COOPERATIVE MODEL. INTEGRATION VERSUS DIFFERENTIATION IN THE FRAMEWORK OF THE FINANCIAL SYSTEM REFORM
}

\begin{abstract}
In this paper will be analyzed the legal framework of Credit Unions, presenting its origin on the half of the nineteenth century in the territory which is called now Germany and the reception and evolution of the institution in Spain to reach the current troubled situation in which, after the financial crisis experienced in recent years, is intensely debated what the future of the sector should be with an announced reform of its legal system.
\end{abstract}

Keywords: credit unions, rural credit banks, Raifeissen, financial system reform, integration, credit cooperative, financial crisis

\section{CONCEPTO, NATURALEZA JURÍDiCA Y ALgUNOS ASPECTOS DE SU RÉGIMEN LEGAL}

Empecemos con un silogismo: si un mundo feliz es mejor (algo que nadie discute) y el dinero, que no da la felicidad, ayuda a conseguirla, el crédito cooperativo tienen mucho que decir en esta pretendida construcción de un mundo mejor, lema de este monográfico de REVESCO, que a su vez fue del día Internacional de la ACI de 2012.

Sin muchas precisión técnica se puede definir el crédito cooperativo como aquél concedido por una cooperativa a sus socios, de manera exclusiva o principal, para satisfacer sus necesidades financieras. Las dos principales manifestaciones del crédito cooperativo son las cooperativas de crédito (Sanchis Palacio, 1997; Palomo Zurdo y Valor Martínez, 2001; Palomo Zurdo, 2001 b) y las secciones de crédito dentro de una cooperativa como forma de internalizar la actividad financiera de la entidad (Fajardo, 1999; Campos y Sanchís, 2005). Centrándonos en la primeras, se distinguen las Cajas Rurales y las Cajas Populares o Laborales y Profesionales, aunque esta clasificación deja de tener su sentido original dada la considerable ampliación de la actividad de las cajas rurales en ámbitos sectoriales distintos a la agricultura o la ganadería, y dada la absorción de algunas de las cajas populares por cajas rurales. Todas estas cajas conforman la denominada Banca Cooperativa, término que se utiliza para designar una modalidad de banca que difiere del resto por las características de su composición, integrada por cooperativas de crédito y otras entidades bancarias y de servicios REVESCO No 117 - MONOGRÁFICO: Las sociedades cooperativas construyen un mundo mejor - ISSN: 1885-8031 - www.ucm.es/info/revesco 
especializados que surgen y tienen su razón de ser en las cooperativas de crédito; y por su forma de funcionamiento, condicionada por los principios cooperativos que rigen en este tipo de sociedades (Del Arco Álvarez, 1979; Palomo Zurdo, 2000).

Precisamente una de las clasificaciones más clásicas de los tipos de cooperativas, ligada al proceso de génesis del movimiento cooperativo, es la que se basa en la causa, necesidad o interés que las hace nacer y las divide en cooperativas de consumo (cuyo objeto es proveer a los socios de bienes de consumo domestico para el sostenimiento propio y familiar), las de producción (que asocian trabajadores para el desarrollo de una actividad industrial) y las de crédito (proveen de créditos a sus socios en mejores condiciones que las del mercado). Esta sistematización, que tuvo acogida legal en nuestro ordenamiento (art. 124 CCOM y art. 2. ${ }^{\circ}$ Ley de Asociaciones de 1887) fue abandonada con el paulatino aumento de las modalidades específicas de cooperativas. Actualmente se suele acudir a un criterio subjetivo como forma de sistematización de estas entidades, esto es, referido a la condición o naturaleza de los sujetos que las pueden constituir y hacer funcionar, lo que permite agruparlas en cooperativas de consumidores (entre las que se incluyen las de crédito) y cooperativas de productores conformadas por productores, profesionales o trabajadores y cuya finalidad es facilitar el ejercicio profesional o empresarial de los socios (cooperativas de trabajadores, profesionales, agrarias, artesanos, etc.) (Vargas Vasserot, 2012: 127).

Las cooperativas de crédito tienen la consideración de entidades de crédito dentro del sistema financiero español, con un peso cuantitativo relativamente importante, y aunque un subtipo de éstas, las cajas rurales, siguen manteniendo su vocación y especialización originaria y tradicional hacia el sector agrario, que sigue constituyendo su mayor fuente de riqueza y clientela, desde hace unos años se ha abierto a nuevos sectores y actividades económicas del entorno social en el que se desarrollan.

Respecto al régimen legal aplicable a estas sociedades, que nos parece un necesario punto de partida en la exposición, recordemos que en España la Ley 27/1999 de Cooperativas (LCOOP), a diferencia de la Ley 3/1987 General de Cooperativas, siguiendo el criterio de delimitación espacial utilizado por la mayoría de leyes de cooperativas autonómicas, declara que sólo es aplicable a las cooperativas que desarrollen su actividad cooperativizada en el territorio de varias Comunidades Autónomas, excepto cuando en una de ellas se desarrolle con carácter principal. No obstante, este reparto competencial entre el Estado y las CC.AA.

REVESCO No 117 - MONOGRÁFICO: Las sociedades cooperativas construyen un mundo mejor - ISSN: 1885-8031 - www.ucm.es/info/revesco 
sobre cooperativas, en el que la legislación del Estado tiene con carácter general el carácter de Derecho supletorio respecto de las CC.AA., resulta muy matizado en el caso particular de las cooperativas de crédito, al tener el Estado reconocidas competencias exclusivas en la fijación de las bases de ordenación del crédito y la banca (art. 149.1.11 ${ }^{\mathrm{a}} \mathrm{CE}$ ). En virtud de este precepto, el Estado promulgó la Ley 13/1989 de Cooperativas de Crédito (LCC), en el que fijaba, de acuerdo con determinadas resoluciones del Tribunal Constitucional, cuáles son estas bases en lo que se refiere a las cooperativas de crédito (disp. final $2^{\mathrm{a}}$ ), cuyo contenido tiene aplicación preferente respecto a las normas autonómicas. En concreto, establece que las cooperativas de crédito se rigen por su ley específica y sus normas de desarrollo, sin perjuicio de las disposiciones que puedan aprobar las CC.AA. en el ejercicio de las competencias que tengan atribuidas en la materia; y por las normas que con carácter general regulan las actividades de las entidades de crédito; siendo de aplicación subsidiaria la legislación de cooperativas (art. 2 LCC).

Pero dentro de esa legislación cooperativa habrá que ver cuando la norma estatal tiene aplicación preferente o subsidiaria, lo que no resulta una cuestión sencilla, como se desprende de la jurisprudencia constitucional sobre el tema (STC 44/1984 de 27 de marzo, STC 165/1985 de 5 de septiembre, STC 86/1989 de 11 de mayo; STC 155/1993 de 6 de mayo y STC 275/2000 de 16 de noviembre). Si con carácter general, la delimitación del ámbito competencial del Estado y las CC.AA. en materia cooperativa se ha resuelto en función del lugar en el que la cooperativa realiza con carácter principal la actividad cooperativizada, es decir, la actividad propia de su objeto social con sus socios, para las cooperativas de crédito el criterio competencial cambia, y así se establece que se aplicará la norma estatal de cooperativas cuando su ámbito de actuación estatutariamente reconocido (no se habla ya de actividad cooperativizada) sea supraautonómico o estatal (art. 104 LCoop). Este criterio se reitera en el Reglamento de desarrollo de la Ley de Cooperativas de Crédito (art. 7.1 RD 84/1993) y en el Reglamento estatal del Registro de Sociedades Cooperativas (art. 2.3 RD 136/2002), que establecen la inscripción en el Registro estatal de sociedades cooperativas de las cooperativas de crédito cuya actividad, sea o no cooperativizada, es decir, se realice con socios o con terceros, exceda del territorio de una Comunidad Autónoma. De lo indicado se desprende que bastará la actuación de la cooperativa de crédito en más de una Comunidad Autónoma, como ocurre con muchas de ellas, para quedar sometida a la normativa estatal y justificar la correspondiente inscripción en el Registro de Cooperativas estatal. Si esta

REVESCO No 117 - MONOGRÁFICO: Las sociedades cooperativas construyen un mundo mejor - ISSN: 1885-8031 - www.ucm.es/info/revesco 
actuación se limita a una determinada Comunidad Autónoma será de aplicación la normativa cooperativa de dicha Comunidad, y será preceptiva la inscripción de la cooperativa en su Registro de Cooperativas.

En cuanto a la constitución de las cooperativas de crédito, el artículo 5.1 LCC exige la autorización previa del Ministerio de Economía y Hacienda, que hoy hay que entender que se hace al Ministerio de Economía y Competitividad, sin perjuicio de las funciones de supervisión que la Ley 10/2014 de Ordenación, Supervisión y Solvencia de Entidades de Crédito (LOSSEC) otorga al Banco de España (arts. 4 y 6). Una vez inscrita en el Registro del Banco de España, deberá procederse a la inscripción de la cooperativa de crédito en el Registro Mercantil que corresponda a du domicilio social [art. 81.1, letra d) RRM] y en el correspondiente Registro de Cooperativas sobre el que ya hemos hablado, en cuyo momento adquirirán personalidad jurídica (art. 5.2 LCC).

Respecto a su naturaleza jurídica, las cooperativas de crédito son sociedades mercantiles que tienen por objeto servir a las necesidades financieras de sus socios y de terceros mediante el ejercicio de las actividades propias de las entidades de crédito. Esta definición, que es la contenida en el art. $1^{\circ}$ de la Ley 13/1989 de Cooperativas de Crédito (LCC), y que de manera sistemática es reiterada en la legislación cooperativa, estatal (art. 104 LCOOP) y autonómica (art. 119.1 Ley Cooperativas País Vasco, art. 102 Ley Cooperativas Cataluña, art. 92 Ley Cooperativas Comunidad Valenciana, etc.), recoge la dualidad jurídica y económica de estas sociedades, como cooperativas y como entidades de crédito. Este artículo 1 LCC, se completa con dos apartados que parecen absolutamente innecesarios que no hacen más que reiterar principios generales reconocidos para todo tipo de cooperativas y que están situados de una forma asistemática en la Ley. De un lado, se dice que las cooperativas de crédito personalidad jurídica propia (apdo. 2); y de otro, mezclando dos cuestiones bien diferentes, establece como ilimitado el número de socios y que la responsabilidad por las deudas sociales sólo alcanza el valor de su aportaciones (apdo. 3). Como cooperativas, son sociedades participativas que asocian a personas con intereses o necesidades socioeconómicas comunes, para cuya satisfacción realizan una actividad empresarial, con carácter preferente con sus socios, con arreglo a los llamados principios cooperativos, que dotan de caracteres propios a estas sociedades.

REVESCO No 117 - MONOGRÁFICO: Las sociedades cooperativas construyen un mundo mejor - ISSN: 1885-8031 - www.ucm.es/info/revesco 
Este precepto, por otra lado, reconoce su naturaleza mixta como entidades de crédito, como reconoce expresamente la LOSSEC [art. 1.2, letra c)] y antes hacía la normativa precedente [art. 2, letra d) del Real Decreto Legislativo 1298/1986, sobre Adaptación del Derecho vigente en materia de Entidades de Crédito al de las Comunidades Europeas, que significaba que quedaban sometidas a los preceptos de la Ley 26/1988 de Disciplina e Intervención de las Entidades de Crédito y al resto de normas que regulan la actividad bancaria). Por otra parte, reconoce desde un inicio la posibilidad de que las cooperativas de crédito no desarrollen su actividad cooperativizada sólo con sus socios, sino que admite las operaciones con terceros.

El carácter netamente mutualista que caracterizaba a las cooperativas de crédito españolas hasta los años sesenta limitó mucho su desarrollo, ya que sólo los socios podían recibir créditos y, aunque podían captar depósitos de terceros no socios, en la práctica, los depositantes y los perceptores de los préstamos eran los mismos. Actualmente la LCC, tras establecer que las cooperativas de crédito deben prestar sus servicios «con atención preferente a las necesidades financieras de sus socios» [art. 4.1 LCC y concordantes autonómicos: Con diferencias de matiza: art. 102.1 LCCAT (primordialmente), art. 92.1 LCCV (prestar especial interés en las operaciones cooperativizadas con sus socios], señala que en cualquier caso el conjunto de las operaciones activas con terceros no podrá alcanzar el 50 por cien de los recursos totales de la entidad. Sin embargo, según la disposición adicional tercera del RCC, se puede superar ese el límite mencionado de operaciones activas con terceros si se cuenta con la pertinente autorización, basada en las causas previstas por la legislación de cooperativas de crédito. La resolución sobre dicha autorización corresponde a la Dirección General del Tesoro y Política Financiera, la cual deberá resolverla en un plazo máximo de tres meses desde su presentación, o a la Comunidad Autónoma competente, siendo preceptivo en todo caso el informe del Banco de España.

La flexibilización de las operaciones con personas no socias ha sido evidente en el ámbito de las cooperativas de crédito, si tenemos en cuenta que la Ley General de Cooperativas de 1987 establecía como límite a las operaciones activas con terceros no socios el 15 por cien de los recursos totales (disp. adic. 6.3). Dicha disposición fue derogada por la Ley 13/1989, en concreto por el artículo 4.2 que ampliaba al 50 por cien la actuación con terceros. En la misma línea, la Ley Régimen Fiscal de Cooperativas, que dedica a este tipo de cooperativas el Título VII, en su artículo 39 contrario sensu, califica de cooperativas protegidas a las de crédito que 
realizan en el ejercicio económico operaciones activas con terceros no socios en cuantía no superior al 50 por cien de los recursos totales de la cooperativa. Esta norma permisiva contrasta con el tenor del derogado Estatuto Fiscal de las Cooperativas, aprobado por Decreto 888/1969, y que entre las causas de pérdida de los beneficios fiscales para las cooperativas de crédito estaba las de realizar operaciones activas con personas o entidades extrañas a las cooperativas que sirvan o a sus asociados [art. 9.4, letra a)]. Respecto a este último aspecto, la realización de operaciones activas con terceros no socios no puede ser superior en el ejercicio económico al 50 por ciento de los recursos totales de la cooperativa (art. 4.2 LCC y art. 39 Ley 20/1990), obstáculo que se suele salvar haciendo socio al cliente que quiera contratar determinadas operaciones con la cooperativa, lo que dado el principio de puertas abiertas que opera en este tipo de sociedades y de variabilidad del capital social, no plantea ningún inconveniente en la práctica. Además, con el objeto de flexibilizar el régimen aplicable a este tipo de cooperativa, no se computa en este tanto por ciento las operaciones realizadas por las cooperativas de crédito con los socios de las cooperativas asociadas, las de colocación de los excesos de tesorería en el mercado interbancario, ni la adquisición de valores y activos de renta fija para la cobertura de los coeficientes legales o para la colocación de los excesos de tesorería (art. 39.2 Ley 20/1990 y art $4.2,2^{\circ}$ LCC).

En el caso concreto de las cooperativas de crédito, la actividad que realiza la cooperativa con sus socios (actividad cooperativizada) consiste en la propia de las instituciones de crédito, que si tradicionalmente ha consistido en recibir fondos del público y aplicarlos por cuenta propia a la concesión de créditos, desde hace unos años consiste en realizar toda clase de operaciones activas, pasivas, de servicios bancarios o parabancarios (financiación hipotecaria, gestión de fondos y patrimonios, seguros, arrendamiento financiero, etc.). El socio se convierte así en cliente de la cooperativa de crédito, existiendo una doble relación contractual entre ambos, por una parte un contrato de sociedad y, por otro, uno o varios contratos bancarios (Vargas Vasserot, 2006: 220 y Martínez Segovia, 2006: 221). La importancia de determinar la naturaleza jurídica de esta relación, en el sentido de si es una relación contractual, una relación societaria o una relación híbrida, deriva de que de ello dependerá el régimen jurídico aplicable para resolver determinadas situaciones de conflicto. En esta caso, a diferencia de lo que ocurre con otros tipos de cooperativas, difícilmente se puede negar que las operaciones que realizan las cooperativas de crédito con sus socios no sean igual que la que éstas u otras entidades realizan con terceros y hay que defender la

REVESCO No 117 - MONOGRÁFICO: Las sociedades cooperativas construyen un mundo mejor - ISSN: 1885-8031 - www.ucm.es/info/revesco 
consideración de los contratos estipulados entre los socios y las cooperativas de crédito como contratos sometidos a condiciones generales de la contratación y a los socios cooperadores como consumidores por destinatarios finales, con toda la protección aplicable a los clientes de las entidades de crédito. Todo esto sin perjuicio de los derechos que tienen los socios en el marco de la estructura organizativa de la entidad.

En el presente trabajo se va a analizar algunos aspectos de esta forma peculiar de ejercicio de la actividad financiera y de la utilidad del modelo cooperativo para la explotación del negocio bancario y vamos a retroceder al origen de la institución y comprobar como ha evolucionado hasta la actualidad, donde muchas veces, en su forma de actuar en el mercado, aparentemente apenas se diferencian del resto de entidades de financieras, lo que nos llevará al actual debate de cuál debe ser el futuro del sector ante la anunciada reforma de su régimen legal en el marco general de la reforma del sistema financiero español.

\section{ORIGEN Y EXPANSIÓN DEL COOPERATIVISMO DE CRÉDITO}

Las cooperativas de crédito surgieron en Europa continental a mediados del siglo XIX, donde de manera casi coetánea aparecen varias experiencias que se pueden calificar de crédito cooperativo, sin perjuicio de tener que reconocer la existencia desde la antigüedad de instituciones de ayuda mutua en las que ya concurrían algunos de los requisitos que lo que se considera el crédito cooperativo. Me refiero de manera particular al conocido como préstamo a la gruesa (foenus nauticus) del Derecho marítimo griego (Brunetti, 1950: 111) y a las sociedades de enterramiento también de origen griego, firmemente desarrolladas en la época romana (Collegia funeraticia, Collegia tenuiorum y Collegia militum) (Goldschmidt, 1913: 55), que son el origen remoto del contrato de seguro, sin contar con las diversas manifestaciones de cooperación crediticia en los gremios y corporaciones medievales (Goldschmidt, 1913, 132; Vivante, 1932: 23-25) y algunas manifestaciones de financiamiento agrícola a través de distintos tipos de asociaciones durante la Edad Moderna en varios puntos del norte y centro de Europa (Gleber, 2005. 73).

Pero mientras las cooperativas de consumo, con los perfiles propios que aún las definen, surgen a mediados del siglo XIX en Inglaterra, con creación de la Rochadle Society os Equitables Pioneers en 1844, experiencia asociativa que se considera el punto de arranque de la cooperación en sentido estricto, es en distintas regiones de lo que hoy es Alemania donde se desarrolla primigeniamente el cooperativismo de crédito, desempeñando una función básica REVESCO No 117 - MONOGRÁFICO: Las sociedades cooperativas construyen un mundo mejor - ISSN: 1885-8031 - www.ucm.es/info/revesco 
como instrumento de financiación de las actividades de determinados colectivos y, en algunos casos, de mera subsistencia.

Oficialmente la primera cooperativa de crédito que se constituyó en el mundo fue en 1843 en la ciudad alemana de Öhringen, que pertenecía al Reino de Wurtemberg, con el nombre de Öhringer Privatspar- und Leihkasse, con el objetivo de ofrecer a sus socios posibilidades de inversión de sus ahorros de forma rentable y segura y garantizarles el otorgamientos de préstamos (Brendel, 2013). Para otros, la primera cooperativa de crédito se constituyó en Bélgica en 1848 (Palomo Zurdo y Valor, 2001: 47) aunque en esa fecha surgió la primera cooperativa belga (Shaffer, 1999: 159], que era de panaderos (bakers) que es fácil confundir con banqueros.

No obstante, se suele considerar a las cooperativas de créditos populares, profesionales o urbanas (Volksbanken) patrocinadas por Franz Herman Schulze-Delitzch, orientadas a servir a las necesidades de comerciantes, artesanos y pequeños industriales de las ciudades, como las primeras de su género y la denominada Eilenburger Vorschussverein constituida en 1850 en esta ciudad de Sajonia, la pionera entre éstas. Su propuesta partía de una concepción economicista y comercial de las cooperativas de crédito, con grandes similitudes con la banca convencional de sociedades por acciones, y cuyo fundamento era la mejora de la situación material de los socios a través de la puesta en común de recursos, por lo que debían reunirse al mayor número de personas con necesidades financieras comunes para lograr la consiguiente acumulación de capital. En esta concepción cooperativa, aunque se partía de una base individualista, se primaba el trato igualitario entre los socios y el carácter democrático de la asociación (un socio un voto). Como juez, político liberal y jurista pragmático, reconoció pronto que la idea del cooperativismo requería de una base legal y participó activamente en la elaboración de la primera ley primera prusiana de cooperativas (1867) que tuvo gran influencia en el contenido de la aún vigente ley alemana de cooperativas (1889).

La otra versión del cooperativismo de crédito, y no menos importante, viene del sector agrario, impulsado de forma decisiva por Frederich Wilhelm Raiffeisen, alcalde de varios municipios de Renania, que movido por sentimientos religiosos y filantrópicos creó las primeras cooperativas de crédito en las áreas rurales (Cajas Rurales o Raiffeisenbanken) para cubrir las acuciantes necesidades financieras de la población campesina. Los antecedentes más cercanos de sus cajas rurales los encontramos en varias sociedades pre-cooperativas de

REVESCO No 117 - MONOGRÁFICO: Las sociedades cooperativas construyen un mundo mejor - ISSN: 1885-8031 - www.ucm.es/info/revesco 
carácter caritativo constituidas por él: la Verein für Selbstbeschaffung von Brot und Früchten asociación constituida en Westerwald en 1847 para mitigar la hambruna y las miserables condiciones de vida de la población campesina a través de compra de harina con el dinero puesto por los ciudadanos más pudientes de la población con la que se hacía el pan que recibían los campesinos empobrecidos contra pagarés a intereses muy bajos; y en la Flammersfelder Hülfsverein zur Unterstützung unbemittelter Landwirte, sociedad de auxilio de los agricultores de Flammersfeld por la que éstos ponían en común sus tierras para pagar con los excedentes obtenidos a los acreedores. Pero el verdadero punto de partida de este movimiento cooperativo se produce en 1864 cuando entiende que los más necesitados se tienen que valer de su propio esfuerzo y que su subsistencia no pueden depender de donaciones, subsidios y caridad, por lo que transforma un establecimiento de beneficiencia de Heddesdorf, cerca de Neuwied, en una sociedad de crédito denominada Heddesdorfer Darlehnskassenverein (Martínez Soto, sin fecha). Esta entidad, que tenía como objetivo ayudar a los agricultores a la adquisición de ganado, semillas, maquinaria y otros insumos agrícolas, se considera la primera cooperativa de crédito basada en los principios raiffesianos, es decir, basada en los principios de auto-ayuda, auto-responsabilidad y auto-administración.

En la evolución del cooperativismo de crédito agrario en Alemania hay que mencionar la labor posterior de Wilhem Hass, que con un marcado carácter liberal y menos fundamentalistas que Raiffeisen (que exclusivamente admitía como socios a agricultores y exigía un respeto absoluto a sus principios) creó a partir de 1872 sus primeras cooperativa agrícolas. La necesaria financiación de las actividades de aprovisionamiento, transformación y comercialización de sus productos se articulaba a través de la creación de redes de cooperación e integración entre las distintas cooperativas. En 1930 se fusionaron las dos grandes centrales del cooperativas de rurales de Alemania. La Reichsverband (sistema Haas) contaba con más de 30.000 cooperativas, de las cuales 14.000 eran cajas de crédito, mientras que la Generalverband (sistema Raiffeisen) agrupaba a 8.000 cooperativas, de las cuales 5.700 eran cajas de ahorros y préstamos (Spar-und Darlehnskasse).

En los años siguientes el cooperativismo de crédito, tanto en su vertiente urbana como rural, se extiende con notable fuerza y rapidez por toda Europa. Ejemplo de lo primero es la fundación en 1864 por León D’Andrimont de la Banca Popular de Lieja, o en Italia la creación en 1865 por el profesor Luigi Luzzatti (Divar, 2012) de la primera Banca Popular en Lodi (Milán). A su vez el cooperativismo rural se implantó en Italia a través de Leone 
Wollemborg y Luigi Cerutti en 1883 y en Francia fue adaptado por Louis Durand. Alphonse Desjardins funda en 1901 en Quebec la primera cooperativa de Crédito en América del Norte (Caisse Populaire de Levis) y en 1909 ayuda a un grupo de franco-americanos católicos de Manchester (New Hampshire) a crear la St. Mary's Cooperative Credit Association, que se considera la primera de este género en Estados Unidos.

El Consejo Mundial de Cooperativas de Ahorro y Crédito (WOCCU por sus siglas en inglés) es la asociación que busca el desarrollo del sistema internacional de cooperativas de ahorro y crédito y promueve su crecimiento sostenible. Fue constituido en 1971 en Madison (Wisconsin) y en la actualidad agrupa a más de cuarenta mil cooperativas, que sirven a aproximadamente ciento veintitrés millones de personas en todo el mundo. En Europa, en concreto, existen alrededor de once mil cooperativas de crédito, que agrupan a treinta y cuatro de socios ostentando, una cuota de mercado próxima al $20 \%$ de los depósitos existentes en el sistema financiero europeo.

\section{RECEPCIÓN Y DESARROLLO DEL COOPERATIVISMO DE CRÉDITO EN ESPAÑA}

En España, la primera cooperativa de crédito que se constituyó fue una caja laboral constituida en Madrid, en 1865, con el atrayente nombre de Manantial de Créditos aunque tuvo una vida muy efímera, aunque señala, no obstante, una experiencia de crédito cooperativo anterior, como fue la Cooperativa de los Papeleros de Buñol (1858), que funcionaba de hecho como una cooperativa de crédito (Palomo Zurdo, 2009: 107). En el ámbito rural, el cooperativismo de crédito penetró fundamentalmente de la mano de la iglesia católica que participó activamente en la creación de las primeras cajas rurales a principios del siglo XX. En rigor, la primera la primera cooperativa de crédito agraria fue constituida en 1891 con el nombre de Caja Rural de Socorros, Préstamos y Ahorros de Javalí Viejo (Murcia), aunque hay que citar que tras la promulgación en 1887 de la Ley de Asociaciones había surgido junto algunos instrumentos de crédito ligados a los Sindicatos Agrarios Católicos (Martínez Soto, 2003: 57-94). De ahí, empezó un goteo continuo de constitución de Cajas Rurales: 1901, Caja Rural en Amusco (Palencia); 1902, varias Cajas Rurales en la provincia de Zamora (San Marcial, Moraleja del Vino, Arenillas y Zamora; 1904, Caja Rural de Olite (Navarra)....]. En 1910, favorecido por la publicación de la Ley de Sindicatos Agrícolas y Pósitos (1906), ya había más de cuatrocientas cincuenta cajas rurales (Terrón

REVESCO N 117 - MONOGRÁFICO: Las sociedades cooperativas construyen un mundo mejor - ISSN: 1885-8031 - www.ucm.es/info/revesco 
Muñoz, 1987: 27). Posteriormente se procedió a la constitución de la Confederación Nacional Católico Agraria (1917) y del Servicio Nacional del Crédito Agrícola (1927), llegando hasta a más de mil cooperativas de crédito existentes en España antes de la Guerra Civil.

El proceso de crecimiento se detuvo tras la promulgación de la Ley de Cooperativas de 1942 y se redujo el número de cajas rurales a unas doscientas al principio de la etapa constitucional, que volvió a incrementarse en los años sesenta, etapa en la que se funda la Unión Nacional de Cooperativas de Crédito (UNACC, 1969) (Palomo Zurdo, 2009: 1101012). En esta época se desarrolla el sector de las cajas populares o laborales, que son cooperativa de crédito especialmente vinculadas con determinadas actividades empresariales y que suelen surgir o formar parte de grupos empresariales, relacionados con la industria, el comercio u otras actividades del sector servicios, como son la Caja Laboral ligada al grupo Mondragón y la Caja Grumeco de Madrid. También a finales de los setenta y principios de los ochenta se fundas las pocas cajas profesionales que ha habido en España, que son cooperativas de crédito orientadas al servicio de determinados colectivos o colegios profesionales, con un ámbito de actuación claramente urbano dirigido a satisfacer sus específicas necesidades financieras (como fue la Caja de Ingenieros y la Caja de Arquitectos).

En los años ochenta comienza una importante crisis del sector con la desaparición de un gran número de cooperativas de crédito que lleva a la puesta en marcha de un Plan de Saneamiento (1983-1989) y a la firma de un convenio de asociación de la mayoría de cajas rurales con el Banco de Crédito Agrícola (BCA) integrado en el ICO. En 1989, por diversos problemas, veinticuatro cajas rurales se desvinculan del BCA y crean la Asociación Españolas de Cajas Rurales (AECR) que conforma el actual Grupo Caja Rural (Sanchís, 1997: 45-59). En 1990 se constituye el Banco Cooperativo Español (BCE), como grupo financiero conformado por la mayoría de cajas rurales cuya vocación es prestar los servicios de una central bancaria a la entidades asociadas.

A través del Grupo Caja Rural, cuya cabeza orgánica la ocupa la AECR, se articula la participación de las cajas rurales miembros en el BCE, Rural Grupo Asegurador (RGA) y Rural Servicios Informáticos (RSI). El sistema de integración utilizado por el grupo es un modelo de banca federada que permite salvaguardar la autonomía de las entidades asociadas que lo forman, sin tener que renunciar al requisito indispensable de operatividad bancaria, al tiempo que se pretende superar las limitaciones de cada entidad por su respectiva dimensión

REVESCO No 117 - MONOGRÁFICO: Las sociedades cooperativas construyen un mundo mejor - ISSN: 1885-8031 - www.ucm.es/info/revesco 
individual y el ámbito geográfico de su actividad. Este grupo de cooperativas de crédito es uno de los ejemplos paradigmático de grupo paritario o por coordinación frente a los típicamente jerárquicos, y su sistema de organización y funcionamiento democrático genera tensiones entre los socios e inestabilidad a la solidez y permanencia del grupo, que es lo que precisamente ha ocurrido en este caso con la salida de varias cajas rurales de su estructura.

\section{LAS COOPERATIVAS DE CRÉDITO EN EL MARCO GLOBAL DE LA REFORMA DEL SECTOR FINANCIERO}

\subsection{El inicio de la expansión del Grupo Cajamar y la descomposición del Grupo Caja Rural}

De la definición legal de grupos cooperativos que contiene el artículo 78.1 LCOOP («conjunto formado por varias sociedades cooperativas, cualquiera que sea su clase y la entidad cabeza de grupo que ejercita las facultades o emite instrucciones de obligado cumplimiento para las cooperativas agrupadas»), se desprende la necesidad de una dirección económica unificada y no un mero control (unidad de decisión, que como señala también el artículo 42 del Código de Comercio al que remite el artículo 4 de la Ley del Mercado de Calores, es el elemento decisivo para individualizar el grupo desde un punto de vista legislativo) (Duque, 2002: 5312). Esto es lógico si se tiene en cuenta la incompatibilidad de la existencia de grupos jerárquicos con los principios cooperativos que rigen en estas sociedades (Embid Irujo, 1998: 14; Alfonso Sánchez, 2000: 147), por lo que los grupos cooperativos a los que se refiere la LCOOP y la mayoría de leyes autonómicas que los regulan tienen que tener carácter de grupos paritarios o por coordinación (Arriba Fernández, 2004: 97).

En estos grupos paritarios no existe una relación de dependencia entre las sociedades agrupadas, de manera que la dirección unitaria no se impone por una entidad superior sino que la gestión del grupo se caracteriza por una coordinación horizontal a través de acuerdos de colaboración mutua entre las cooperativas miembros. De este modo, en los grupos paritarios la dirección unitaria es el elemento que aporta cohesión al grupo y en su determinación intervienen, en igualdad, todas las sociedades del grupo. La unidad de decisión, por tanto, recorre un camino inverso que en los jerárquicos o de subordinación, por lo que se pueden representar el grupo como una pirámide invertida en la que la cabeza de grupo se sitúa en una posición inferior y en la base, pero por arriba las sociedades que lo componen. La obligatoriedad de las instrucciones que emita la entidad cabeza de grupo dimana de la REVESCO No 117 - MONOGRÁFICO: Las sociedades cooperativas construyen un mundo mejor - ISSN: 1885-8031 - www.ucm.es/info/revesco 
legitimidad del interés del grupo, que aglutina los intereses de las cooperativas que lo integran. En la estructuras de grupos cooperativos deben regir los principios cooperativos, y entre ellos, el principio de libre adhesión, por lo que queda siempre a voluntad de las cooperativas de base la posible separación del grupo e incluso la posibilidad de la expulsión de uno de sus miembros por el resto (Sacristán Represa, 1982: 375; Embid Irujo, 1998: 174).

Y esto es lo que ha sucedido en el Grupo Caja Rural, en el que con una composición tan heterogénea como es la de las cajas rurales, por su gran diferencia en tamaño, intereses y estrategias, es difícil lograr una postura común de actuación y se han dado sonoros casos de baja de miembros ante importantes diferencias entre los modelos de gestión y estrategias de expansión desarrolladas por sus miembros, como veremos a continuación.

Las profundas diferencias entre el modelo de gestión preconizado por la Asociación Española de Cajas Rurales (AECR) y por Cajamar (entidad resultante de la fusión de las Caja Rural de Almería con la de Málaga en 2000, que antes había absorbido a la Campo de Cartagena y Grumeco), provocaron evidentes tensiones en el seno del grupo que terminaron con la expulsión de la entidad en 2002 del Grupo Caja Rural ante la negativa de la Cajamar a ampliar capital en la poco rentable filial de informática (RSI). Las tensiones volvieron a resurgir cuando la AECR llevó a los tribunales el proceso de fusión por absorción llevada a cabo por Cajamar con la Caja Rural del Duero (2007), y que supuso la primera fusión en España de cooperativas de crédito de distintos ámbitos autonómicos. Para intentar cerrar esta larga disputa, en 2008 y a instancia del Banco de España, se cerró un acuerdo entre Cajamar y la AECR por el que se ambas partes desistían de los contenciosos judiciales iniciados y se aceptaba el pago de una importante cantidad de dinero por las participaciones de Cajamar en el Banco Cooperativo, en la compañía de Seguros RGA y en RSI. Pero, como veremos, fueron sólo paños calientes.

\subsection{Procesos de concentración de cooperativas de crédito en plena crisis del sistema} financiero

Las cooperativas de crédito llegaron al inicio de la crisis sumando el mayor número de entidades del sector. En concreto, en 2008 había ochenta y tres cooperativas se repartían por todo el país, con una papel ciertamente muy destacado de la Comunidad Valenciana, con treinta y seis entidades, que significaba el $45 \%$ del total. Siete años más tarde, a finales del 2014, el panorama ha cambiado sustancialmente, con sesenta y cinco cooperativas de crédito REVESCO No 117 - MONOGRÁFICO: Las sociedades cooperativas construyen un mundo mejor - ISSN: 1885-8031 - www.ucm.es/info/revesco 
(Banco de España, 2014), lo que ha significado un notable proceso de concentración, llevado a cabo de motu proprio por las entidades, aunque hay que reconocer que en ciertos casos los procesos de fusión por absorción llevados a cabo han sido incentivados por el propio Banco de España ante la mala situación financiera de algunas entidades de este tipo.

A finales de 2009 se constituyó el denominado Grupo Cooperativo Cajamar (Cajamar, Caja Campo, Caja Rural de Albalat y Caja Rural de Casinos al que fueron sumándose otras entidades: Caja de Crédito de Petrel, Caixa Rural de Turís, etc.) cuyos miembros, a través de una fusión fría articulada por un Sistema Institucional de Protección (SIP), mantenían su soberanía, personalidad jurídica, órganos de gobierno y de dirección propios, sedes sociales así como la plena gestión de su fondo de educación y promoción. El SIP suponía aglutinar bajo una entidad de mayor tamaño que actuaba como cabecera a un grupo de cooperativas más pequeñas que mantenían su identidad aunque mutualizaban beneficios (y pérdidas) y consolidaban con la firma que lideraba y controlaba el proyecto. Poco después en 2010, quince cajas rurales de la Comunidad Valenciana suscribieron un SIP para la constitución de un grupo cooperativo con el nombre de Grupo Cooperativo Cajas Rurales del Mediterráneo (CRM) liderado por Ruralcaja (Caja Rural Provincial de Valencia), entidad resultante de la fusión de varias cajas rurales de la Comunidad Valenciana (Alicante, Elche, Valencia, y Credicoop de Castellón. El Grupo CRM, estaba compuesta además por Caixa Rural Torrent, Crèdit Valencia, Caixaltea, CR Burriana, Caixacallosa, Caixa Rural Nules, Caixalqueries, Caja Rural de Cheste, Caixa Rural D'Alginet, Caja Rural de Villar, Caixa Rural Vilavella, Caixa Rural Almenara, Caixa Rural Xilxes y Caixa Rural Vilafamés).

Tras estos dos importantes procesos de integración mediante fusiones frías, entre 2010 y 2011 se abrió una nueva etapa de concentraciones, pero en las que primó el componente territorial, es decir, las rurales optaron por integrarse con entidades del mismo o próximo origen territorial, lo que además fue incentivado desde las instancias políticas autonómicas que aspiraban a grandes cajas rurales para compensar la desaparición de las cajas de ahorro por la bancarización del sector (Luque Frías, 2012). Recordemos que el Real Decreto-ley 11/2010, de órganos de gobierno y otros aspectos del régimen jurídico de las Cajas de Ahorros, diseñaba un nuevo modelo organizativo de este tipo de entidades financieras de carácter público-privado basado en una doble alternativa: el ejercicio indirecto de la actividad financiera de la caja a través de una entidad bancaria o la transformación de la misma en una fundación de carácter especial traspasando su negocio a otra entidad de crédito. De las ocho 
cajas de ahorro que quedaban en 2014 la mayoría habían traspasaron su actividad financiera a entidades bancarias creadas a tal efecto (Unicaja, Caja Granada, Caja Murcia, Caja Santander y Cantabria, Caja Baleares, Caja de Gipuzkoa y San Sebastián) y sólo han quedado como típicas cajas de ahorros la valenciana Caixa Ontiyent y la Caixa Pollença de las Islas Baleares.

Dado que las dudas sobre el sistema financiero español continuaban, el Real Decretoley 2/2011 para el reforzamiento del sistema financiero abrió otra fase en el proceso de reestructuración y saneamiento de las entidades de crédito. Pero tal como establecía el comunicado del Banco de España (10 de marzo de 2011), los sesenta grupos consolidables de cooperativas de crédito que existían en ese momento en España cumplían con los requisitos de capital exigidos (capital principal del 8\%), lo que permitió al sector de cooperativas de crédito continuar sin urgencias los procesos de consolidación e integración iniciado años antes (UNACC, 2013).

Volviendo a los procesos de concentración de las cooperativas de crédito del bienio 2010-2011, en algún caso se siguió con la técnica del SIP, como ocurrió con el Grupo Cooperativo Ibérico que integró bajo un mismo grupo consolidable a Caja del Sur, Caja Rural de Córdoba y Caja Rural de Extremadura, aunque esta última se salió posteriormente del proyecto; y en con el grupo Solventia, liderado por la Caja Rural de Almendralejo, que integró a varias cajas rurales de la provincia Córdoba (Cajas de Adamuz, Baena, Cañete de las Torres Nueva y Carteya ) y a la Caja de Utrera. Se optó, en cambio, por fusiones propiamente dichas, para la creación de Nueva Caja Rural de Aragón nacida de la unión en 2011 de Multicaja (Caja Rural Aragonesa y de los Pirineos) con otra caja rural aragonesa (Cajalón) y que opera comercialmente con el nombre de Bantierra; y de Globalcaja, fruto de la fusión en ese mismo año de las cajas rurales de Albacete, Cuenca y Ciudad Real, que ya había absorbido a la de la Roda, y a la que se acaba de añadir Caja Rural de Mota del Cuervo (2014). En 2012 nace Cajaviva Caja Rural, de la fusión de las cajas rurales de Burgos, Fuentepelayo, Segovia y Castelldans.

Pero de nuevo el gran movimiento de integración del momento lo lideró Cajamar, que en 2012 llevó a cabo la creación del grupo consolidable Caja Rurales Unidas tras la fusión por absorción de la valenciana Ruralcaja, que atravesaba una situación financiera difícil muy afectada por la burbuja inmobiliaria. Con esta integración, impulsada por el propio Banco de España ante el riesgo de insolvencia de la que era en ese momento la segunda caja rural de

REVESCO No 117 - MONOGRÁFICO: Las sociedades cooperativas construyen un mundo mejor - ISSN: 1885-8031 - www.ucm.es/info/revesco 
España por volumen de activos, se agrupaban las dos SIP que encabezaban ambas entidades, sumando veintidós entidades y logrando una clara posición de liderazgo en el sector de cooperativas de crédito. En 2013 Cajamar absorbió a la Caja Rural de Canarias y a varias cajas que formaban parte del Grupo Cajas Rurales Unidas (Caja Rural de Casino y Credit Valencia), con lo que se inicia el principio del fin de la entidad.

\section{LA ACTUAL POLARIZACIÓN DEL SECTOR Y LAS INCERTIDUMBRE ANTE LA ANUNCIADA REFORMA DE SU RÉGIMEN LEGAL}

En la actualidad (finales de 2014), tomando en consideración los grupos consolidados que se han ido formando en los últimos años, el número de cooperativas de crédito registradas en el Banco de España ha quedado reducido a menos de cuarenta, ya que de las sesenta y cinco inscritas actualmente, treinta y una han quedado integradas en alguno de los grupos constituidos.

De los datos numéricos, en cuanto a volúmenes de activos, cifras de negocio, número de socios y de clientes, se desprende la gran polarización del sector. De un lado el Grupo Cajamar y entidades asociadas (con un volumen de activo superior a 40.000 millones de euros y que ostenta más del $50 \%$ del negocio gestionado por el sector de las cajas rurales españolas, con 4 millones de clientes y más de 1.300 .000 socios) y de otro el resto de cajas rurales que funcionan de forma independiente, cuyo líder es la Caja Rural de Navarra (unos 8.000 millones de euros de activos) que es de las pocas con un tamaño relativamente importante (sólo ocho más superan los 2.000 millones de euros). En medio la Laboral Kutxa (activos cercanos a los 25.000 millones de euros), resultado de la fusión de la vascas Caja Laboral e Ipar Kutxa (2013) pero que tiene características propias respecto del resto de cooperativas de crédito de España.

Esta diferenciación económica se ha traducido en un enfrentamiento político derivado de las muy diferentes maneras de entender el futuro del sector. De un lado el Grupo Cajamar y otras entidades asociadas, que apuestan por un proceso de expansión territorial, derivado, entre otras cosas, por las cada vez más importantes necesidades de financiación de la agricultura intensiva almeriense que es el origen de la entidad y del incremento de competencia del sector que requiere unas bases financieras sólidas; y de otro el resto de cajas rurales agrupadas en la AECR y representadas por la UNACC. El penúltimo paso de estas estrategias divergentes se ha dado a principios de 2014, cuando las diecinueve cajas rurales REVESCO No 117 - MONOGRÁFICO: Las sociedades cooperativas construyen un mundo mejor - ISSN: 1885-8031 - www.ucm.es/info/revesco 
del Grupo Cooperativo Cajamar y otras trece más (aparte de Cajamar, que ostenta el 90\% del BCC, participan en el mismo las siguientes entidades: Caixapetrer; Caja Rural de Cheste; Caixaltea; Caixaturis; Caixa Rural Almenara; Caixa Rural Nules; Caixa Sant Vicent; Caja Rural de Villar; Caixacallosa; Caixa Rural de Xilxes; Caixa Rural Vila-real; Caixa Rural Vilavella; Caixa Rural Burriana; Caixa Rural Vilafamés; Caixa Rural Torrent; Caixa Rural d'Alginet; Caixalqueries y Caixa Albalat) constituyeron el Banco de Crédito (Social) Cooperativo S.A., calificado por el Banco de España como un grupo consolidable y el acuerdo suscrito entre las entidades participantes como un SIP. En esas fechas se procede a la liquidación del Grupo Cooperativo Cajas Rurales Unidas y se da de alta al nuevo Grupo Cooperativo Cajamar, con lo que se retoma la denominación anterior del grupo.

El último capítulo la confrontación entre el grupo Cajamar y las entidades a él asociadas y el resto de cajas rurales se ha producido recientemente (noviembre de 2014) con la salida de la UNACC. Un año antes, Cajamar había comunicado su decisión de abandonar la patronal española de las cooperativas de crédito al considerar que no estaba representada suficientemente en la asociación, ya que ésta no le reconocía como un grupo consolidable sino como una simple entidad sin el peso que realmente le correspondía como representante de un gran número de cajas rurales. Finalmente la UNACC aceptó la baja solicitada por el Grupo Cajamar (noviembre de 2014) que acaba de ingresar en la Asociación Española de la Banca (AEB) a través de su cabecera, el Banco de Crédito Cooperativo (diciembre de 2014). Se culmina así un largo proceso que ha sido tachado de bancarización de dicha cooperativa de crédito, pero que sus protagonistas consideran como la única alternativa para asegurar el futuro del sector y que, por las técnicas de integración utilizadas, no se pone peligro la subsistencia del cooperativismo de crédito, ya que las diecinueve entidades que componen el Banco de Crédito Cooperativo mantienen su estructura, sus socios y su singularidad específica, con la debida proyección social en el territorio donde desarrollan su actividad financiera de manera principal. La fórmula de integración adoptada sigue los pasos de otros sistemas afines de banca cooperativa con larga tradición y éxito en Europa, algunos de los cuáles se clasifican entre los primeros grupos bancarios del continente, como son el Okobank finlandés, el Rabobank en los Países Bajos, el Österreichische Raiffeisenbanken austríaco, el Crédit Agricole en Francia o el sistema alemán Volksbanken-Raiffeisenbanken.

Lo cierto es que en la nueva Unión Bancaria Europea, el Grupo Cooperativo Cajamar, por su tamaño y volumen de activos, es considerado una de las catorce entidades REVESCO No 117 - MONOGRÁFICO: Las sociedades cooperativas construyen un mundo mejor - ISSN: 1885-8031 - www.ucm.es/info/revesco 
significativas del sistema financiero español, y como tal su supervisión corresponde al Mecanismo Único de Supervisión (MUS), formado por el Banco Central Europeo (BCE) y las autoridades nacionales competentes de los países participantes. Pues bien, en octubre de 2014 el grupo ha superado con holgura el test de estrés realizado por el Banco Central Europeo lo que acredita su solvencia y su solidez financiera (con una ratio CET1 de 7,99\%, 2,49 puntos porcentuales más que el 5,5\% establecido en el escenario adverso, y una ratio CET1 de $10,17 \%$, frente al $8 \%$ fijado como valor de referencia en el escenario base, es la única cooperativa de crédito de España que ha participado en este proceso y supera el análisis de la calidad de los activos y la prueba de resistencia), lo que tiene su mérito dado que en poco tiempo, y sin acudir a ayudas públicas ni al Fondo de Reestructuración Ordenada Bancaria (FROB), ha asumido la costosa absorción de Ruralcaja que estaba a punto de ser intervenida por el Banco de España por graves problemas de solvencia.

Pero aparte del debate sobre el futuro financiero del sector está la cuestión de la necesaria subsistencia del modelo cooperativo, que algunos ven peligrar de prosperar la anunciada reforma del marco jurídico de las cooperativas de crédito con objeto de bancarizarlo. Para el Grupo Caja Rural una reforma que potencien los procesos de integración elevando los requisitos económicos y de solvencia necesarios para realizar la actividad financiera a través de cooperativas de crédito supondría el final del modelo cooperativo (IUDESCOOP, 2014).

Lo cierto es que ahora mismo no se sabe por dónde puede ir la reforma anunciada. En un primer momento (2013 y principios de 2014) las noticias eran que desde el Ministerio de Economía se iba a potenciar las integraciones y consolidación de grupos de cooperativas de crédito, como forma de unificar el sector que sigue estando muy atomizado, con una cuota de mercado muy reducida respecto a la que ostentan sus homónimos de la Unión Europea (6\% frente al 20\%). El Ministro de Economía, Luis de Guindos anunció el 13 de enero de 2014 en el Congreso de los Diputados el inicio de la transformación de las cooperativas de crédito a través de una actualización de su régimen jurídico en pro de la concentración del sector. Esto venía refrendado por el Banco Central Europeo que recomendaba en un Informe de esas mismas fechas que dado que el régimen legal de las cooperativas de crédito en Espala no había sido revisado desde hacía tiempo, a la luz de la reciente experiencia financiera, podría estar justificada una revisión de su reglamentación. Uno de los aspectos centrales de la reforma propuesta inicialmente, e incentivada por el Banco Central Europeo, sería la reforma 
de la estructura orgánica de estas sociedades para adaptarla a los nuevos criterios del gobierno corporativo.

Con la mirada puesta en la necesidad de modernización y mejora del gobierno corporativo de la gran sociedad cooperativa, se deberían desarrollar legislativamente algunos aspectos relacionados con los órganos sociales de las cooperativa de crédito teniendo en cuenta algunas de las reflexiones, recomendaciones y avances legislativos hechos en la última década en el campo del Derecho de las sociedades cotizadas, lo que lleva al importante juego de competencias entre órganos, la separación de poderes y funciones en el seno del Consejo Rector, su composición con la posible existencia de consejeros externos, la delegación de competencias del órgano de administración en profesionales de la gestión y la conveniente desconcentración de poder del Presidente de las cooperativas de crédito. Por otra parte, es un hecho que desde hace años el legislador ha venido adaptando el ordenamiento jurídico en aquellas áreas de la regulación societaria que han merecido una intervención de naturaleza imperativa en materia de buen gobierno corporativo y muchas de estas disposiciones son aplicables a algunas cooperativas de crédito por emitir valores al público.

En este sentido hay que señalar la Ley 44/2002 de Medidas de Reforma del Sistema Financiero, que modifica la LMV y por la que se obligó a las sociedades cotizadas a contar con un Comité de Auditoría; o la Ley 26/2003 por la que se modifican la LMV y la LSA con el fin de reforzar la transparencia de las sociedades anónimas cotizadas, que obligó a estas sociedades a contar con los reglamentos de la junta general y del consejo de administración respectivamente. También hay que mencionar los avances que introdujo la Ley 2/2011 de Economía Sostenible, en materia de transparencia de los sistemas retributivos y la Orden ECC/461/2013, de 20 de marzo, por la que se determinan el contenido y la estructura del informe anual de gobierno corporativo, del informe anual sobre remuneraciones y de otros instrumentos de información de las sociedades anónimas cotizadas, de las cajas de ahorros y de otras entidades que emitan valores admitidos a negociación en mercados oficiales de valores.

No obstante de esta necesaria esta aproximación legal, en la práctica siguen existiendo notables diferencias del modelo cooperativo con el modelo de las sociedades de capital y, por ello, cuando se han intentado trasladar los avances del gobierno corporativo a las cooperativas se choca con una realidad distinta de la que sólo quedan fuera las grandes cooperativas y los

REVESCO No 117 - MONOGRÁFICO: Las sociedades cooperativas construyen un mundo mejor - ISSN: 1885-8031 - www.ucm.es/info/revesco 
grupos cooperativos (Alfonso Sánchez y Sánchez Ruiz, 2007: 1057). Todo lo anterior, hace aconsejable plantearse desde las peculiaridades de la cooperativa de crédito, la necesidad de introducir normas que se orienten hacia mejorar su gestión, sin que quepa según entendemos, limitarse a seguir el modelo pensado para las entidades bancarias. Pero la modernización y mejora de la estructura orgánica de las cooperativas de crédito es absolutamente necesaria.

Conviene precisar que la LCC no presta demasiada atención a los órganos de las cooperativas de crédito (art. 9), por lo que para precisar su régimen legal hay que acudir al RLCC (arts. 18-29) y subsidiariamente a la correspondiente ley cooperativa que sea de aplicación, como se deduce del artículo 2 in fine LCC y expresamente declara el artículo 29 de su Reglamento de desarrollo, que establece que «en lo no previsto sobre estructura orgánica de las cooperativas de crédito por éste u otros capítulos del presente Real Decreto se estará a lo dispuesto en la Ley 13/1989 y en la restante normativa, estatal o autonómica, sobre Cooperativas, que resulte de aplicación». De este modo, algunas de las importantes novedades que sobre la materia incorpora la Ley 31/2014 que se modifica la Ley de Sociedades de Capital para la Mejora del Gobierno Corporativo (LMGC), pueden y deben llegar a las cooperativas de crédito sea por el juego de la remisión normativa (por ejemplo, art. 43 LCOOP en materia de responsabilidad de administradores) sea a través de la recepción directa por la LCC en su futura redacción. Recordemos que el objetivo final de la LMGC es velar por el adecuado funcionamiento de los órganos de gobierno y administración de las empresas españolas, para conducirlas a las máximas cotas de competitividad; generar confianza y transparencia para con los accionistas e inversores nacionales y extranjeros; mejorar el control interno y la responsabilidad corporativa de las empresas españolas; y asegurar la adecuada segregación de funciones, deberes y responsabilidades en las empresas, desde una perspectiva de máxima profesionalidad y rigor. $\mathrm{Y}$ todo esto parece a todas luces extensible a las cooperativas de crédito.

Pero esta posible reforman intensa del estatuto legal de las cooperativas de crédito con posterioridad (mediados de 2014) se ha estado matizando desde el Banco de España, que habla de una reforma mucho más liviana en la cual se realizarían ajustes o retoques a la Ley de Cooperativas de Crédito y a su Reglamento de Desarrollo, En este sentido, Fernando Restoy, Subgobernador del Banco de España, tras declarar en junio de 2014 que se estaba estudiando una reforma de la regulación de las cooperativas de crédito, aseguraba que los ajustes regulatorios preservarán el núcleo esencial del actual modelo de negocio de las 
cooperativas de crédito, sin cuestionar en absoluto sus señas de identidad. En esta esfera se circunscribe la mención que se ha efectuado por la disposición final segunda de la Ley 10/2014 de Ordenación, Supervisión y Solvencia de Entidades de Crédito, normativizando la obligación de que el reembolso de capital social en caso de baja del socio necesite el acuerdo favorable del Consejo Rector (art. 7.4 LCC, que establece que las aportaciones serán reembolsadas a los socios en las condiciones que se señalen reglamentariamente y siempre que lo autorice el Consejo Rector, pero que no podrá aprobarse dicho reembolso cuando ocasione una cobertura insuficiente del capital social obligatorio, reservas y coeficiente de solvencia y que las aportaciones no podrán presentar entre sí privilegio alguno en su prelación en caso de concurso o liquidación de la cooperativa). De esta manera se quiere dejar claro el carácter de recursos propios de las aportaciones al capital social, que tras la conocida como NIC32 comprometía la calificación contable como recursos financieros ajenos en virtud del derecho incondicional a su reembolso que tiene el cooperativista en el momento de causar baja en la sociedad. Aunque el RD 1309/2005 modificó el RLCC al añadir un nuevo apartado segundo al artículo 10, para que determinadas aportaciones al capital social de la cooperativas de crédito puedan ser calificadas como recursos propios porque el Consejo Rector de estas sociedades pueda rehusar incondicionalmente su reembolso, se ha aprovechado la promulgación de la LOSSEC para dejar claro esto y disipar cualquier duda. Hay que tener en cuenta que para la cuantía de los recursos propios de estas sociedades es fundamental, tanto para los ratios de solvencia como porque establece los límites para operar con terceros. El tratamiento contable de las aportaciones de los socios a las cooperativas como deudas en vez de como neto puede tener efectos negativos en las calificaciones de riesgos de las agencias de rating, aspecto que puede ser especialmente relevante las cooperativas de crédito (Vargas Vasserot, 2011: 33).

También encajaría en esta línea de reforma moderada el aumento de los mínimos de capital social que debe tener la entidad. Recordemos que respecto al capital social de estas entidades, que debe estar íntegramente suscrito y desembolsado en efectivo, el artículo 6 LCC establece que el Gobierno fijará su cuantía mínima en función del ámbito territorial y del total de habitantes de los municipios comprendidos en dicho ámbito. Actualmente, tal como establece el art. 3 RLCC, el capital social mínimo es de poco más de un millón de euros para las de ámbito local que operen en municipios de menos de cien mil habitantes; en algo más de 4.8 millones de euros para las que tengan sede o ámbito que incluya los municipios de Madrid

REVESCO No 117 - MONOGRÁFICO: Las sociedades cooperativas construyen un mundo mejor - ISSN: 1885-8031 - www.ucm.es/info/revesco 
o Barcelona o de ámbito supra autonómico; y para las que estén entre unas y otras, 3,6 millones de euros. Cifras que a todas luces han quedado escasas en comparación con las requeridas al resto de entidades bancarias [18 millones de euros exige el art. 2.1, letra b) del Real Decreto 1245/1995 sobre creación de Bancos, actividad transfronteriza y otras cuestiones relativas de las entidades de crédito, redactado por el apartado dos del artículo primero del R.D. 256/2013].

Sin embargo últimamente (finales de 2014), se ha ido conociendo la escasa voluntad actual de las administraciones competentes de seguir impulsando esta posible reforma del régimen legal de las cooperativas de crédito ya que una reforma tan puntual tiene escaso recorrido y sentido en el actual marco de reestructuración del sector financiero y el de mayor profundidad tampoco parece es atractivo en el actual escenario con tantas voces en contra (MORÓN, 2014).

\section{CONCLUSIONES}

En todo caso y como conclusión, lo que es un hecho es que las cooperativas de crédito han sorteado mejor que otras entidades de crédito la reciente crisis financiera y están basadas en un modelo de negocio eficiente y sostenible, que debe ser apoyado como vía alternativa a la banca convencional, especialmente cuando el crédito no está llegando con la fluidez deseada a determinadas capas de la población y sectores empresariales (con este propósito, CEPYME de la provincia de Alicante ha iniciado los trámites para la creación de una cooperativa de crédito para dar financiación a las pequeñas y medianas empresas de esta provincia y del resto de la Comunidad Valenciana, a las que también quiere captar como socias para este proyecto) En Europa, donde existe un gran desarrollo del movimiento cooperativo, cada vez son más importantes y frecuentes los documentos oficiales que reconocen la gran resistencia de las cooperativas a la reciente crisis financiera y consideran a este tipo de empresas como una herramienta fundamental en el futuro económico de la Unión Europea. Y es una evidencia que las cooperativas han demostrado ser más resistentes que las empresas convencionales a la crisis que recientemente ha azotado a Europa (2008-2012), tanto atendiendo a los índices de empleo como al cierres de actividades y, es sintomático, que incluso en los peores años de la crisis económica se llegó a crear empleo por cooperativas en determinados sectores (especialmente cooperativas de crédito, de trabajo asociado y de servicios).

REVESCO No 117 - MONOGRÁFICO: Las sociedades cooperativas construyen un mundo mejor - ISSN: 1885-8031 - www.ucm.es/info/revesco 
En el Informe sobre La contribución de las cooperativas a la salida de la crisis, aprobado por el Parlamento Europeo en junio de 2013 (2012/2321 (INI)), se afirma lo siguiente: «Como modelo, las cooperativas ha demostrado poder satisfacer necesidades nuevas y estimular la creación de empleo mejor que otros modelos, gracias a su gran capacidad para adaptarse a los cambios y mantener su actividad en situación de riesgo permaneciendo fieles a su misión. En períodos de recesión, las cooperativas pueden promover eficazmente el emprendimiento a escala microeconómica, ya que permiten a pequeños emprendedores asumir responsabilidades empresariales». Esta gran resistencia se debe, por una parte, en modelo cooperativo de gobernanza, que se basa en la propiedad conjunta, la participación y el control económico y democrático de la organización y gestión por parte de los socios; y, por otra, a su método característico de acumulación de capital, que es menos dependiente de la evolución de los mercados financieros y está asociado tanto a la asignación de los excedentes a los fondos de reserva, en parte irrepartibles, así como a la mezcla en los objetivos de la entidad de intereses sociales y económicos equilibrados. Como señala el Informe, «este modelo contribuye a garantizar que las cooperativas adopten un enfoque a largo plazo que pasa de generación en generación y las afianza en la economía local, contribuyendo al desarrollo local sostenible y garantizando que no se deslocalizan, incluso cuando adquieren una dimensión internacional».

Pero el cumplir con el modelo cooperativo no es una cuestión de tamaño, sino de actitud. Por ello, sin perjuicio de que es necesaria garantizar la solvencia financieras de estas entidades y modernizar su régimen legal, que ha quedado muy envejecido con el paso de los años (se han cumplido ya veinticinco años desde la promulgación de la LCC), se debe permitir la coexistencia de los dos modelos comentados de cooperativas de crédito, que volviendo al principio de este estudio, me recuerda mucho a la contraposición entre las cooperativas de Schulze-Delitzch y Raifeissen, ambas igualmente validas para el desarrollo del espíritu cooperativo.

REVESCO No 117 - MONOGRÁFICO: Las sociedades cooperativas construyen un mundo mejor - ISSN: 1885-8031 - www.ucm.es/info/revesco 


\section{BIBLIOGRAFÍA}

AIZEGA ZUBILLAGA, C. y VALIÑANI GONZÁLEZ (2003) Las cooperativas de segundo grado, grupos cooperativos y otras formas de colaboración económica. REVESCO. Revista de Estudios Cooperativos, Núm. 79, pp. 20 y s.

ALFONSO SÁNCHEZ, R. (2000) Integración cooperativa y sus técnicas de realización: la Cooperativa de Segundo Grado. Valencia: Tirant Lo Blanch.

ALFONSO SÁNCHEZ, R. y SÁNCHEZ RUIZ, M. (2007) Aspectos generales sobre el buen gobierno de las cooperativas y de los grupos cooperativos, RDM, Núm. 266, p. 1057.

ARRIBA FERNÁNDEZ, M.L. (2004) Derecho de grupos de sociedades. Madrid: ThomsonCivitas, pp. 97 y s.

BRENDEL, M. (2013), Geschichte der Volksbank Hohenlohe (Öhringer Privatspar- und Leihkasse): http://genossenschaftsgeschichte.info/volksbank-hohenlohe-oehringerprivatspar-und-leihkasse-182.

BRUNETTI, A. (1950) Derecho Marítimo Privado (Parte histórica - De los buques), t. I. Barcelona: Bosch, pp. 111 y ss.

CAMPOS, V. y SANCHÍS, J.R. (2005) Las secciones de crédito de las cooperativas en España. Revista de Desarrollo Rural y Cooperativismo Agrario, Núm. 9, pp. 35-52.

DEL ARCO ÁLVAREZ (1979) Cooperativas de crédito y crédito cooperativo. REVESCO. Revista de Estudios Cooperativos, Núm. 4, 1979, pp. 3-38.

DIVAR, J. (2012), Luigi Luzzatti, «pionero del crédito popular». Boletín de la Asociación Internacional de Derecho Cooperativo, Núm. 46, pp. 327-331.

DUQUE, J. (2002) El concepto de grupo de sociedades y su desarrollo en Derecho español, Libro homenaje a Sánchez Calero, T. V. Madrid: MacGraw Hill, pp. 5312 y ss.

EMBID IRUJO, M. (1998) Problemas actuales de la integración cooperativa. RDM, Núm. $227, \mathrm{p}, 14$

FAJARDO, G (1999) Las secciones de crédito en el ordenamiento jurídico español. CIRIECEspaña, Núm. 32, pp. 9-39.

GLEBER, P. (2005) Von der Urhorde zur eG. Auf der Suche nach der ältesten Genossenschaft. Bankinformation, Núm. 10, p. 73.

GOLDSCHMIDT, L. (1913) Storia universale del Diritto commerciale. Turín: UTET 
IUDESCOOP (2014) Manifiesto en favor de la continuidad de las Cooperativas de Crédito y Cajas Rurales de la Comunidad Valenciana, al que hasta ahora se han adherido más de cincuenta instituciones públicas y privadas:

http://www.manifiestocajasruralesvalencianas.org/mantenimiento-de-las-cajas-rurales/

LUQUE FRÍAS, J. (2012) Crisis económica y cooperativas de crédito: el reto de la eficiencia. Granada: Tesis Doctoral:

http://0-hera.ugr.es.adrastea.ugr.es/tesisugr/21007196.pdf.

MARTÍNEZ SEGOVIA, F. (2006), La relación cooperativizada entre la sociedad cooperativa y su socios: naturaleza y régimen jurídico". Revista de Derecho de Sociedades, Núm. 25, pp. 203-234.

MARTÍNEZ SOTO, A.P. (2003) Los orígenes del cooperativismo de crédito agrario en España, 1890-1934. CIRIEC-España, Núm. 44, pp. 57-104.

MARTÍNEZ SOTO, A.P. (sin fecha) El cooperativismo alemán entre 1860-1930: sistemas y evolución: http://seha.info/pdfs/ii_asociacionismo/II-pascual2.pdf

PALOMO ZURDO (2000), Pasado, presente y futuro de la Banca Cooperativa en España. Valencia, pp. 13 y ss.

PALOMO ZURDO, R.J. (Coord.) (2001) Banca cooperativa y economía social en Europa. Madrid: UNACC, $379 \mathrm{p}$.

PALOMO ZURDO, R.J. y VALOR MARTÍNEZ, C. (2001, b) Banca Cooperativa: entorno financiero y proyección social. Madrid: UNACC, $325 \mathrm{p}$.

PALOMO ZURDO, R.P. (2009) Cooperativismo de crédito: historia de las cooperativas de crédito en España, Diccionario de Economía Social. Madrid: Ecobook, pp. 105-110.

SACRISTÁN REPRESA, M. (1982) El grupo de estructura paritaria: caracterización y problemas, RDM, Núms. 165-166, pp. 375 y ss.

SANCHIS PALACIO, J.R. (1997) El crédito cooperativo en España. Valencia: CIRIEC.

SHAFFER, J. (1999) Historical Dictionary of the Cooperative Movement. Boston

TERRÓN MUÑOZ (1987) Las Cajas Rurales de España. Nacimiento, auge y perspectivas del cooperativismo agrario crediticio en España. Granada.

UNACC (2013) Las cooperativas de crédito, la consolidación dentro del modelo: http://www.unacc.com/Portals/0/Otras\%20Publicaciones/Libros/Reestructuraci\%C3\%B3n $\% 202013 . p d f$

VARGAS VASSEROT, C. (2006), La actividad cooperativizada y las relaciones de la cooperativa con sus socios con terceros. Cizur Menor: Thomson-Aranzadi.

REVESCO No 117 - MONOGRÁFICO: Las sociedades cooperativas construyen un mundo mejor - ISSN: 1885-8031 - www.ucm.es/info/revesco 
VARGAS VASSEROT, C. (2011) Aportaciones exigibles o no exigibles: ésa es la cuestión. CIRIEC-Jurídica, Núm. 22, pp. 75-119.

VARGAS VASSEROT, C. (2012) Clases y clasificaciones de cooperativas. Deusto Estudios Cooperativos, Núm.1, pp. 125-142.

VIVANTE, C. (1932) Tratado de Derecho mercantil, vol. 1. Madrid: Reus. 